\title{
Metabolic Syndrome and Associated Factors Among HIV-infected Patients at Bafoussam Regional Hospital, Cameroon
} \author{
Jules-Roger Kuiate, * \\ ${ }^{1}$ Department of Biochemistry, University of Dschang, Dschang, Cameroon \\ ${ }^{2}$ HIV Care Centre, Bafoussam Regional Hospital, Bafoussam, Cameroon \\ ${ }^{3}$ Department of Biochemistry, University of Yaounde 1, Yaounde, Cameroon \\ ${ }^{4}$ Department of Public Health, University of Dschang, Dschang, Cameroon
}

Joel Martial Diesse ${ }^{1}$, Cyril Wilfried Missinga ${ }^{2}$, Aude Ngueguim Dougue ${ }^{3}$, Emeline Zogning Makemjio ${ }^{4}$, Stephen Tamekou Lacmata ${ }^{1}$, Jean Paul Dzoyem ${ }^{1}$,

Email address:

jdiesse1@yahoo.fr (Joel M. D.), cyril.missinga@yahoo.com (Cyril W. M.), audedougue@yahoo.fr (Aude N. D.), emiliezog@yahoo.fr (Emeline Z. M.), lacmatastephen@yahoo.fr (Stephen T. L.), jean.dzoyem@univ-dschang.org (Jean P. D.), jrkuiate@yahoo.com (Jules-Roger K.)

${ }^{*}$ Corresponding author

\section{To cite this article:}

Joel Martial Diesse, Cyril Wilfried Missinga, Aude Ngueguim Dougue, Emeline Zogning Makemjio, Stephen Tamekou Lacmata, Jean Paul Dzoyem, Jules-Roger Kuiate. Metabolic Syndrome and Associated Factors Among HIV-infected Patients at Bafoussam Regional Hospital, Cameroon. European Journal of Clinical and Biomedical Sciences. Vol. 6, No. 4, 2020, pp. 63-70. doi: 10.11648/j.ejcbs.20200604.13

Received: August 12 2020; Accepted: August 22, 2020; Published: September 7, 2020

\begin{abstract}
The use of highly active antiretroviral therapy (HAART) transformed HIV infection to a chronic disease, and the complexity of the physiological disorders generated leads to the disruption of body fat distribution and insulin resistance. The resulting metabolic syndrome has rarely been investigated among people living with HIV/AIDS in Cameroon. The aim of the current work was to determine the prevalence of metabolic syndrome and associated factors among people living with HIV/AIDS under HAART at the Bafoussam Regional Hospital in Cameroon. A retrospective, cross-sectional study was conducted to collect demographic, clinical and therapeutic data from 371 people living with HIV/AIDS and who are under HAART at the Bafoussam Regional Hospital from November 2017 to February 2019. Abbott Real-time HIV-1 system, FACSCOUNT cytometer and FULLYSMART automates were used to determine HIV RNA level, CD4 cell count and biochemical parameters respectively. The metabolic syndrome was defined according to the International Diabetes Federation (IDF) and the National Cholesterol Education Program -Adult Treatment Panel III (NCEP-ATPIII) criteria. The overall prevalence of metabolic syndrome was $37.74 \%$ by IDF and $28.84 \%$ by ATPIII. Among patients with metabolic syndrome, HDL-hypocholesterolemia was the most prevalent feature (92.14\%). We found that aging (OR, 1.05; $p, 0.005)$, HIV RNA level (OR, 3.42; $\mathrm{p}, 0.001)$, family history of metabolic and coronary heart disease (OR, 2.24; P, 0.04), alcohol consumption (OR, 4; P, $0.004)$ and nutritional supplements $(\mathrm{OR}, 3.5 ; \mathrm{P}<0.001)$ were the independent predictors of metabolic syndrome. Male sex (OR, $0.22 ; \mathrm{p},<0.001)$, use of traditional medicines $(\mathrm{OR}, 0.28 ; \mathrm{P}<0.001)$, Cotrimoxazole prophylaxis (OR, $0.45 ; \mathrm{p}, 0.007)$ and Lamivudine-Tenofovir-Efavirenz antiretroviral regimen $(\mathrm{OR}, 0.26 ; \mathrm{p}<0.001)$ were protective factors. The prevalence of metabolic syndrome is on the increase among people living with HIV/AIDS in our study population. Both HIV related factors and traditional risk factors were associated with metabolic syndrome.
\end{abstract}

Keywords: Metabolic Syndrome, People Living with HIV/AIDS, HAART, Traditional Risk Factors 


\section{Introduction}

Metabolic syndrome has become a public health issue with the westernization of lifestyles [1]. It is a condition that regroups a set of risk factors for type II diabetes and cardiovascular diseases, starting with a pro-inflammatory condition, visceral adipogenesis and insulin resistance [2, 3]. Two definitions of metabolic syndrome are used worldwide and all include the following metabolic disorders: high blood glucose level, high triglyceride level, low HDL cholesterol level, high blood pressure and obesity [1].

During HIV infection, metabolic co-morbidities including components of metabolic syndrome have been observed [4, 5]. Indeed, HIV infection is characterized by chronic activation of the immune system, progressive destruction of lymphoid tissue architecture with disturbances of the intestinal microbiota and chronic systemic inflammation [6, 7]. Furthermore, micronutrient deficiencies that promote an inflammatory state and adipogenesis have been generally reported during HIV infection [8, 9]. More important, high burden of risk factors for coronary disease including lipodystrophies, dyslipidemia and hypertension, have been reported among HIV patients receiving or not antiretroviral treatments $[10,11]$.

Although HAART has significantly reduced mortality and morbidity associated with HIV infection, it is also responsible for toxicities ranging from simple grade 1 or 2 intolerance to long-term life-threatening side effects $[12,13]$. Dysmetabolic protease inhibitors (PIs) are associated with dyslipidemia and insulin resistance $[14,15]$. Reverse transcriptase inhibitors have sometimes been associated with metabolic disorders; they are associated with impaired mitochondrial function, manifested by an increase in blood lactate levels [16, 17]. Stavudine is most frequently involved [14].

According to previous studies, the prevalence of metabolic syndrome among PLWHA, particularly those under HAART, is increasing $[14,16]$. The treatment protocol for PLWHA recommends systematic monitoring of metabolic complications. In Cameroon, limited financial resources do not allow systematic monitoring of all these complications in HIV care centres and very limited studies has been done to assess the impact of metabolic syndrome and the associated factors among PLWHA, while prescription of metabolically neutral drugs and healthy lifestyles should improve life quality of these patients. We hypothesized that certain treatment regimens and lifestyles would be associated with a high prevalence of metabolic syndrome in our study population of PLWHA. In the present study we aimed to assess the prevalence of metabolic syndrome in HIV-infected patients at a major hospital designated for HIV care in West region of Cameroon and to evaluate the association between the use of two main drug regimens made up of PIs, nucleoside reverse transcriptase inhibitors (NRTIs) and non-nucleoside reverse transcriptase inhibitors (NNRTIs) and traditional risk factors with the development of metabolic syndrome.

\section{Materials and Methods}

\subsection{Study Design and Ethical Consideration}

This is a retrospective, cross-sectional study that took place from November 2017 to February 2019 in the HIV care centre of BRH. It was approved by the National Committee on Research Ethics for Human Health (reference number: 2017/11/955/EC/CNERSH/SP) and was conducted in accordance with the Declaration of Helsinki on Good Clinical Practice. Participants gave written informed consent. They were all part of the national cohort of PLWHA and were regularly followed up by physicians of HIV care centre of Bafoussam Regional Hospital (BRH) according to the national treatment guidelines for adults with HIV infection. They were recruited base on the following inclusion criteria: have a complete medical record, being HIV-positive on HAART for at least 12 months, be between 18 and 55 years old, have no history of co-infection with hepatitis $\mathrm{B}$ or $\mathrm{C}$ viruses, do not receive any other form of chemotherapy except Cotrimoxazole, do not use contraceptive hormones. The exclusion criteria were as follows: pregnancy, incomplete measurement and laboratory test results, willingness of the patient to withdraw from the study at any stage.

\subsection{Data Collection}

The data collection was carried out during routine visits of patients with the assistance of physicians in charge of their follow-up and laboratory technicians of BRH. A standardized questionnaire and patient medical records were used to investigate the therapeutic history, demographic, clinical, and other associated factors of metabolic syndrome including dietary habits. Demographic (gender, age, ethnicity, place of residence, occupation), therapeutic history (post-exposure prophylaxis, HAART regimens, traditional treatment), lifestyles and dietary habits (consumption of food supplements, tobacco, alcohol, carbohydrate, fat and protein intakes assessed from a simplified consumption frequency questionnaire) were recorded. Therapeutic compliance was assessed using Morisky's standardized questionnaire [18]. Physical activity was evaluated using the International Physical Activity Questionnaire [19] and special reports of the American College of Sports Medicine and the American Heart Association [20]. The duration of HIV infection and that of HAART and medical history were obtained from the patient's medical record. HAART was determined through the recording of the last 12 months and defined as the use of at least three agents from three classes of ARVs agents according to the national treatment guidelines for adults with HIV infection; NRTIs, PIs and NNRTIs.

\subsubsection{Measurement of Anthropometric Parameters}

All anthropometric measurements were performed by a single investigator and in accordance with WHO standards [21]. Height was measured to the nearest $0.5 \mathrm{~cm}$, with the participant standing without shoes, heels together and head in the horizontal plane using a height gauge. Weight was measured to the nearest $0.1 \mathrm{~kg}$ using a SECA scale. The waist 
circumference was taken to the nearest $0.5 \mathrm{~cm}$. It was measured midway between the lower margin of the ribs and the iliac crest in the horizontal plane. Body mass index (BMI) was calculated as weight in $\mathrm{kg}$ divided by the square of the height in $\mathrm{m}$. Blood pressure was taken with an OMRON electronic sphygmomanometer (M6, Japan). After the patient reached HIV care for his medical examination and rested for at least $10 \mathrm{~min}$, two measurements were taken at $10 \mathrm{~min}$ intervals on the right arm with the patient seated. The average of the measurements was calculated and used in the analyses.

\subsubsection{Measurement of Biological Parameters}

Total cholesterol, HDL-cholesterol, LDL-cholesterol, triglycerides and glycemia were measured using 12 hours fasting blood through a biochemical analysis robot (FULLYSMART, Japan) by colorimetric methods. HIV RNA level and CD4 cell count were measured using the Abbott m2000rt Real-Time HIV-1 system (CA, USA) (limit of detection, 40 copies $/ \mathrm{mL}$ ) and the FACSCOUNT cytometer (Becton Dickinson, USA) respectively. All assay have been validated by quality control.

\subsection{Definition of Metabolic Syndrome}

The definition of the International Diabetes Federation (IDF) [1] and that of the National Cholesterol Education Program-Adult Treatment Panel III (NCEP-ATP III) [22] were used. According to the IDF criteria, metabolic syndrome involves; a waist circumference $\geq 94 \mathrm{~cm}$ for men and $\geq 80 \mathrm{~cm}$ for women, or a BMI $\geq 30 \mathrm{Kg} / \mathrm{m}^{2}$ for the population of sub-Saharan Africa (mandatory criterion) with two other of the following criteria: blood pressure $\geq 130 / 85 \mathrm{mmHg}$, fasting blood glucose $\geq 1 \mathrm{~g} / \mathrm{L}$, fasting triglyceridemia $\geq 1.50 \mathrm{~g} / \mathrm{L}$ and HDL cholesterolemia $<0.40 \mathrm{~g} / \mathrm{L}$ (men) and $<0.50 \mathrm{~g} / \mathrm{L}$ (women) or specific treatments. According to the ATPIII criteria, the presence of at least 3 of the 5 aforementioned biological parameters is required with the waist circumference threshold $\geq 102 \mathrm{~cm}$ (men) and $\geq 88 \mathrm{~cm}$ (women).

\subsection{Statistical Analysis}

The data were analysed using EPI Info version 7.1.5. We were able to derive frequencies and proportions from the descriptive analysis, logistic regressions allowed us to determine factors associated with metabolic syndrome. A significance level of 0.05 and a relative risk value compared to one (1) allowed us to conclude on the relationship between the dependent variable and the independent variables of the study.

\section{Results}

\subsection{Socio-demographic and Clinical Characteristics of Patients}

The univariate analysis excluding the 5 IDF criteria for metabolic syndrome showing socio-demographic and clinical characteristics of the studied population are presented in Table 1. $99 \%$ of the population participated in more than 150 minutes of weekly walking. Bamileke ethnic group represented $60.92 \%$ of the population, urban dweller $59 \%$ and night workers $16.71 \%$. The high majority of patients 324 $(87.33 \%)$ were currently receiving HAART regimens including two NRTIs and one NNRTIs while $90.29 \%$ of patients were receiving dietary advice. Patients in this study tended to be older, with 270 patients (72.78\%) being over 40 years. Patients with age $\geq 40$ years also had a significantly higher frequency of metabolic syndrome $(p=0.01)$. We noticed a predominance of women $267(71.97 \%)$ with a sex ratio W/M of 2.6. Women also had a significantly high frequency of metabolic syndrome $(p<0.001)$. Patients not receiving Cotrimoxazole prophylaxis $(\mathrm{p}=0.002)$ and patients receiving nutritional supplements $(p=0.003)$ had a significantly high frequency of metabolic syndrome. Alcohol consumers $(p=0.004)$, day-worker $(p=0.001)$ and patients with a family history of metabolic and coronary heart diseases were more likely to have metabolic syndrome $(\mathrm{p}<0.001)$.

Furthermore, patients with a duration of HIV infection and duration of HAART more than 6 years $(\mathrm{P}=0.01$ and $\mathrm{p}=0.008$ respectively), HIV RNA level $>40$ copies $/ \mathrm{mL}(\mathrm{p}=0.03), \mathrm{CD} 4$ cell count $>350$ cells $/ \mathrm{mm}^{3}(\mathrm{p}=0.04)$, patients who had started HAART at stage I of HIV infection $(p=0.002)$ and patients receiving antiretroviral regimens including PIs $(p=0.009)$, were more at risk of metabolic syndrome. Nevertheless, compared with patients receiving antiretroviral regimens including Efavirenz, those receiving Nevirapine were more likely to have metabolic syndrome $(\mathrm{p}<0.001)$. Additionally, a significantly high proportion of patients with poor treatment compliance had metabolic syndrome $(\mathrm{p}=0.04)$.

\subsection{Biological Characteristics of Patients}

The prevalence of metabolic syndrome and its individual components are shown in table 2 . The overall prevalence of metabolic syndrome were $37.74 \%$ and $28.84 \%$ according to IDF and ATP III criteria, respectively. The prevalence of individual components were shown to be: high waist circumference $68.46 \%$ (36.34\% men and $80.90 \%$ women) using IDF threshold value, low HDL-cholesterol levels $64.15 \%$ (44.23\% men and $71.91 \%$ women), high fasting glucose levels $40.6 \%$ (with $14.82 \%$ diabetes), high triglyceride levels $36.66 \%$ and, high blood pressure $33.42 \%$. $29.11 \%$ of patients had no metabolic abnormality, $8.36 \%$ had one metabolic abnormality, $24.80 \%$ had two metabolic abnormalities, $21.83 \%$ had three metabolic abnormalities, $7.00 \%$ had four metabolic abnormalities and $8.89 \%$ had five metabolic abnormalities.

\subsection{Factors Associated with Metabolic Syndrome}

The results of the logistic regression of factors associated with metabolic syndrome are shown in Table 3. After multivariate analysis, alcohol consumption, aging, family history of metabolic and coronary heart disease, consumption of nutritional supplements and detectable HIV RNA level were the independent predictors of metabolic syndrome. While, 3TC-TDF-EFV regimen, use of traditional medicines, Cotrimoxazole prophylaxis and male sex appear as protective 
factors against metabolic syndrome.

Table 1. Socio-demographics and clinical characteristics of the study population according to metabolic syndrome status.

\begin{tabular}{|c|c|c|c|c|c|c|c|}
\hline \multirow{2}{*}{ Variables } & \multirow{2}{*}{ Modalities } & \multirow{2}{*}{$\begin{array}{l}\text { All patients } \mathbf{N}=371 \\
\mathbf{N}(\%)\end{array}$} & \multicolumn{2}{|c|}{ Metabolic syndrome } & \multicolumn{2}{|c|}{ No metabolic syndrome } & \multirow{2}{*}{$P$ value } \\
\hline & & & $\mathbf{n}$ & $\%$ & $\mathbf{N}$ & $\%$ & \\
\hline \multirow{2}{*}{ Sex } & Men & $104(28.06)$ & 18 & 17.31 & 86 & 82.69 & \multirow{2}{*}{$<0.001$} \\
\hline & Women & 267 (71.97) & 122 & 45.69 & 145 & 54.31 & \\
\hline \multirow{2}{*}{ Age } & $<40$ & $101(27.22)$ & 28 & 27.72 & 73 & 72.28 & \multirow{2}{*}{0.01} \\
\hline & $\geq 40$ & $270(72.78)$ & 112 & 41.48 & 158 & 58.52 & \\
\hline \multirow{2}{*}{ Ethnic group } & Bamileke & $226(60.92)$ & 91 & 40.27 & 135 & 59.73 & \multirow{2}{*}{0.21} \\
\hline & Other & $145(39.08)$ & 49 & 33.79 & 96 & 66.21 & \\
\hline Residence & Urban & $219(59.03)$ & 79 & 36.07 & 140 & 63.93 & 0.43 \\
\hline & Yes & $173(46.63)$ & 81 & 46,82 & 92 & 53.18 & \\
\hline Family history of MCHD & No & $198(53.40)$ & 59 & 29.8 & 139 & 70.2 & $<0.001$ \\
\hline & Day & $309(83.29)$ & 126 & 41.72 & 176 & 58.28 & \\
\hline Work time & Night & $62(16.71)$ & 14 & 20.29 & 55 & 79.71 & 0.001 \\
\hline Phycical activity (min/week) & $\geq 150$ & 368 (99.19) & 139 & 37.77 & 229 & 62.23 & 1 \\
\hline rinysical activily (IIII)/ week) & $<150$ & $3(0.81)$ & 1 & 3.33 & 2 & 66.67 & 1 \\
\hline Fruit and vegetable & $\leq 4 /$ day & $336(90.57)$ & 128 & 38.10 & 208 & 61.90 & 0.66 \\
\hline Frut and vegetaole & $>4 /$ day & $35(9.43)$ & 12 & 34.29 & 23 & 65.71 & 0.00 \\
\hline & Yes & $74(19.95)$ & 39 & 52.70 & 35 & 47.30 & \\
\hline Nutritional supplement & No & $297(80.05)$ & 101 & 34.01 & 196 & 65.99 & 0.003 \\
\hline & White meat only & $38(10.24)$ & 14 & 36.84 & 24 & 63.16 & \\
\hline Meat & All & $333(89.76)$ & 126 & 37.84 & 207 & 62.16 & 0.90 \\
\hline & Refined oil only & $44(11.86)$ & 16 & 36.36 & 28 & 63.64 & \\
\hline Fat & All & $327(88.14)$ & 124 & 37.92 & 203 & 62.08 & 0.84 \\
\hline & Slow only & $51(13.75)$ & 25 & 49.02 & 26 & 50.98 & \\
\hline Sugar & All & $320(86.25)$ & 115 & 35.94 & 205 & 64.06 & 0.01 \\
\hline & Yes & $65(15.52)$ & 25 & 38.46 & 40 & 61,54 & \\
\hline Smoking & No & $306(82.48)$ & 115 & 37.58 & 191 & 62.42 & 0.89 \\
\hline & Yes & $41(11.05)$ & 24 & 58.54 & 17 & 41.46 & \\
\hline Alcohol & No & $330(88.95)$ & 116 & 35.15 & 214 & 64.85 & 0.004 \\
\hline & Routine & $101(27.22)$ & 47 & 46.53 & 54 & 53.47 & \\
\hline & Stage I & $154(41.51)$ & 72 & 46.75 & 82 & 63.25 & \\
\hline Stage at the HAART initiation & Stage II & $94(22.64)$ & 30 & 35.71 & 54 & 64.29 & 0.002 \\
\hline & Stage $=>$ III & $133(35.85)$ & 38 & 28.57 & 95 & 71.43 & \\
\hline & {$[1-2]$ years } & $63(16.98)$ & 16 & 25.40 & 47 & 74.60 & \\
\hline Duration of HIV infection & {$[3-5]$ years } & $41(11.05)$ & 11 & 26.83 & 30 & 73.17 & 0.01 \\
\hline & [6--] years & 267 (71.97) & 114 & 42.70 & 153 & 57.30 & \\
\hline & [1-2] years & $80(21.56)$ & 20 & 25.00 & 60 & 75.00 & \\
\hline Duration of HAART & [3-5] years & $57(15.36)$ & 22 & 38.60 & 35 & 61.40 & 0.008 \\
\hline & [6--] years & $234(63.07)$ & 98 & 41.88 & 136 & 58.12 & \\
\hline CD4 cell count (cells $/ \mathrm{mm}^{3}$ ) & $\leq 350$ & $52(14.01)$ & 13 & 25.00 & 39 & 75.00 & \\
\hline CD4 cell count (cells/mm') & $>350$ & $319(85.99)$ & 127 & 39.81 & 192 & 60.19 & 0.04 \\
\hline & $\leq 40$ & $222(59.84)$ & 74 & 33.33 & 148 & 66.67 & \\
\hline HIV RNA level (copies/mL) & $>40$ & $149(40.16)$ & 66 & 44.30 & 83 & 55.70 & 0.03 \\
\hline & Use of NNRTIs & $324(87.33)$ & 114 & 35.19 & 210 & 64.81 & \\
\hline Antıretroviral regimens & Use of PIs & $47(12.67)$ & 26 & 55.32 & 21 & 44.68 & 0.009 \\
\hline & Yes & $245(66.04)$ & 75 & 30.61 & 170 & 69.39 & \\
\hline 3TC-TDF-EFV & No & $126(33.96)$ & 65 & 51.59 & 61 & 48.41 & $<0.001$ \\
\hline & Yes & $44(11.86)$ & 28 & 63.64 & 16 & 36.36 & \\
\hline $3 \mathrm{IC}-\mathrm{IDF}-\mathrm{N} V \mathrm{P}$ & No & $327(88.14)$ & 112 & 34.25 & 215 & 65.75 & $<0.001$ \\
\hline & Yes & $28(7.55)$ & 8 & 28.57 & 20 & 71.43 & \\
\hline $31 C-A \angle I-N V P$ & No & $343(92.45)$ & 132 & 38.48 & 211 & 61.52 & 0.30 \\
\hline & Yes & $17(4.58)$ & 6 & 35.29 & 11 & 64.71 & \\
\hline $31 \mathrm{C}-\mathrm{IDF}-\mathrm{LPV} / \mathrm{r}$ & No & $354(95.41)$ & 134 & 37.85 & 220 & 62.15 & 0.83 \\
\hline 3TC-AZT-L PV/r & Yes & $11(2.96)$ & 8 & 72.73 & 3 & 27.27 & 0.025 \\
\hline S1C-ALI-LPV/I & No & $360(97.04)$ & 132 & 36.67 & 228 & 63.33 & 0.025 \\
\hline & Yes & $13(3.50)$ & 9 & 69.23 & 4 & 30.77 & \\
\hline SIC-IDF-AIV & No & $358(96.50)$ & 131 & 36.59 & 227 & 63.41 & 0.03 \\
\hline & Yes & $208(56.06)$ & 64 & 30.77 & 144 & 69.23 & \\
\hline Cotrimoxazole & No & $163(43.94)$ & 76 & 46.63 & 87 & 53.37 & 0.002 \\
\hline
\end{tabular}




\begin{tabular}{|c|c|c|c|c|c|c|c|}
\hline \multirow{2}{*}{ Variables } & \multirow{2}{*}{ Modalities } & \multirow{2}{*}{$\begin{array}{l}\text { All patients } \mathrm{N}=371 \\
\mathrm{~N}(\%) \\
\end{array}$} & \multicolumn{2}{|c|}{ Metabolic syndrome } & \multicolumn{2}{|c|}{ No metabolic syndrome } & \multirow{2}{*}{$P$ value } \\
\hline & & & $\mathrm{n}$ & $\%$ & $\mathbf{N}$ & $\%$ & \\
\hline \multirow{2}{*}{ Traditional medicines } & Yes & $143(38.54)$ & 46 & 32.17 & 97 & 67.83 & \multirow{2}{*}{0.08} \\
\hline & No & $228(61.46)$ & 94 & 41.23 & 134 & 58.77 & \\
\hline \multirow{2}{*}{ HAART compliance } & Good & $99(26.68)$ & 29 & 29.29 & 70 & 70,71 & \multirow{2}{*}{0.04} \\
\hline & Poor & $272(73.32)$ & 111 & 40.81 & 161 & 59.19 & \\
\hline
\end{tabular}

MCHD: metabolic and coronary heart disease; 3TC: Lamivudine; TDF: Tenofovir; EFV: Efavirenz; NVP: Nevirapine; AZT: Zidovudine; LPV/r: Lopinavir boosted with Ritonavir; ATV: Atazanavir; NNRTIs: non-nucleoside reverse transcriptase inhibitors, PIs: Protease inhibitors.

Table 2. Biological characteristics of the study population.

\begin{tabular}{|c|c|c|c|}
\hline Variables & Modalities & patients (n) & Percentage (\%) \\
\hline \multirow{3}{*}{ Blood Pressure (mmHg) } & $\geq 130 / 85$ & 124 & 33.42 \\
\hline & $<130 / 85$ & 247 & 66.58 \\
\hline & $<25$ & 113 & 30.46 \\
\hline \multirow[t]{2}{*}{$\operatorname{BMI}\left(\mathrm{Kg} / \mathrm{m}^{2}\right)$} & $\geq 25<30$ & 158 & 42.59 \\
\hline & $\geq 30$ & 100 & 26.95 \\
\hline \multirow{3}{*}{ Glycemia (g/L) } & $<1$ & 222 & 59.84 \\
\hline & $\geq 1<1.26$ & 94 & 25.34 \\
\hline & $\geq 1.26$ & 55 & 14.82 \\
\hline \multirow{2}{*}{ Triglyceride (g/L) } & $<1.5$ & 235 & 63.64 \\
\hline & $\geq 1.5$ & 136 & 36.66 \\
\hline \multirow{2}{*}{ Total Cholesterol $(\mathrm{g} / \mathrm{L})$} & $<2$ & 267 & 71.97 \\
\hline & $\geq 2$ & 104 & 28.04 \\
\hline \multirow{2}{*}{ LDL Cholesterol (g/L) } & $<1.6$ & 322 & 86.79 \\
\hline & $\geq 1.6$ & 49 & 13.21 \\
\hline \multicolumn{4}{|l|}{ HDL Cholesterol (g/L) } \\
\hline \multirow{2}{*}{ 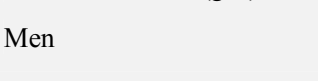 } & $\leq 0.4$ & 46 & 44.23 \\
\hline & $>0.4$ & 58 & 55.77 \\
\hline \multirow{2}{*}{ Women } & $\leq 0.5$ & 192 & 71.91 \\
\hline & $>0.5$ & 75 & 28.09 \\
\hline \multicolumn{4}{|c|}{ ATPIII Waist Circumference $(\mathrm{cm})$} \\
\hline \multirow{2}{*}{ Men } & $<102$ & 91 & 87.5 \\
\hline & $\geq 102$ & 13 & 12.5 \\
\hline \multirow{2}{*}{ Women } & $<88$ & 87 & 32.58 \\
\hline & $\geq 88$ & 180 & 67.42 \\
\hline \multicolumn{4}{|l|}{ IDF Waist Circumference $(\mathrm{cm})$} \\
\hline \multirow{2}{*}{ Men } & $<94$ & 66 & 63.44 \\
\hline & $\geq 94$ & 38 & 36.34 \\
\hline \multirow{2}{*}{ Women } & $<80$ & 51 & 19.1 \\
\hline & $\geq 80$ & 216 & 80.9 \\
\hline \multirow{6}{*}{ Metabolic Syndrome score } & 0 & 108 & 28.84 \\
\hline & 1 & 31 & 8.36 \\
\hline & 2 & 92 & 24.80 \\
\hline & 3 & 81 & 21.83 \\
\hline & 4 & 26 & 7.00 \\
\hline & 5 & 33 & 8.89 \\
\hline \multicolumn{4}{|c|}{ Metabolic syndrome prevalence } \\
\hline IDF & l & 140 & 37.74 \\
\hline ATPIII & 1 & 107 & 28.84 \\
\hline
\end{tabular}

BMI: body mass index; LDL: low density lipoprotein; HDL: high density lipoprotein: IDF: International Diabetes Federation: ATP III: Adult Treatment Panel III.

Table 3. Logistic regression of factors associated with metabolic syndrome.

\begin{tabular}{lll}
\hline Variable & Odd Ratio (95\% CI) & P value \\
\hline Age & $1.05(1.02-1.09)$ & 0,005 \\
Sex (Men/Women) & $0.22(0.1-0.45)$ & $<0.001$ \\
Family history of MCHD (Yes/No) & $2.24(1.28-3.92)$ & 0.004 \\
Nutritional supplements (Yes/No) & $3.5(1.75-7)$ & $<0.001$ \\
HIV RNA level > 40/ 40$)$ & $3.42(1.92-6.95)$ & 0.001 \\
Alcohol (Yes/No) & $4(1.54-10.94)$ & 0.004 \\
Traditional medicines (Yes/No) & $0.28(0.14-0.54)$ & $<0.001$ \\
Cotrimoxazole (Yes/No) & $0.45(0.25-0.8)$ & 0.007 \\
3TC-TDF-EFV (Yes/No) & $0.26(0.12-0.57)$ & $<0.001$ \\
\hline
\end{tabular}

CI: confidence interval; MCHD: metabolic and coronary heart disease; 3TC: Lamivudine; TDF: Tenofovir; EFV: Efavirenz. 


\section{Discussion}

We found a high prevalence rate of metabolic syndrome and its associated risk factors in the study population compared with reported prevalence among different groups of people in the general population in Cameroon. However, the prevalence rate was similar to that of a study conducted earlier on a well-matched population of HIV-infected people using IDF criteria [23]. Traditional factors, HAART and HIV-related factors were associated with metabolic syndrome.

Among the 371 patients involved in this study, we found the predominance of women, usually described in the population of PLWHA [24]. Demographic and several other socio-cultural factors could be an explanation [25]. Contrary to the observation during the decades of the beginning of the pandemic where young adults were more heavily affected by HIV [26], this study is consistent with the finding of Mapoure et al. [24] with the predominance of adults over 40 years. The quality of upstream response systems, which determines the epidemiological evolution of HIV disease, could explain this trend towards an aging population of PLWHA [27].

Considering either IDF or ATP III criteria, the prevalence rate of metabolic syndrome and its individual components were high in the study population compared with those reported in different groups of Cameroonian HIV-uninfected $[28,29]$. However, there was a significantly low prevalence rate of metabolic syndrome by ATP III criteria (28.84\%) compared with the prevalence rate by IDF criteria $(37.74 \%)$ in the present work. On the other hand, the work conducted by Dimodi et al. [23] among PLWHA showed prevalence of metabolic syndrome very close to our results. Some patients with metabolic syndrome according to ATP III criteria had no metabolic syndrome as per IDF criteria in the present study. This result was not consistent with the observation made by Elgalib et al. [15]. The observe discrepancy revealed the importance of the criteria adopted for estimating the prevalence rate of metabolic syndrome in a given population.

In this study, a HIV RNA level $>40$ copies $/ \mathrm{mL}$ was found to be a predicting factor of metabolic syndrome [OR 3.42 (1.92 $6.95) ; \mathrm{p}=0.001]$. Previous evidence indicates an association that can be modified by HAART between viral replication and CD4 cell count [30], on the other hand Bernal et al. [31] have reported a positive association between metabolic syndrome and an undetectable HIV RNA level.

HAART has already been pointed out to explain the high prevalence rate of metabolic disorders in PLWHA [14-16]. However HAART was not an independent predictor of metabolic syndrome in the present study. Our observation is consistent with a previous report from Brazil [32]. Nevertheless, the antiretroviral regimen 3TC-TDF-EFV was positively associated with metabolic syndrome [OR, 0.26 $(0.12-0.57) ; \mathrm{p},<0.001]$. 3TC-TDF-EFV including metabolic neutral ARVs compound [30] is the first intention antiretroviral regimen mostly prescribed at the HIV care centre of BRH and this could explain this result.

An important finding in this work was the association of traditional medicines with metabolic syndrome as a protective factor [OR, $0.28(0.14-0.54) ; \mathrm{p},<0.001$ ], probably due to the wide range of health benefits attributed to the herbal drugs. Cotrimoxazole prophylaxis was a protective factor against metabolic syndrome [OR, $0.45(0.25-0.8) ; \mathrm{p}, 0.007]$, this might be due to the fact that, this antibiotic is prescribed to almost all immunological non-responders to prevent the occurrence of opportunistic co-morbidities that exacerbates inflammatory response during HIV infection [33].

Age was an independent predictor of metabolic syndrome [OR, 1.05 (1.02-1.09) p, 0.005]. Previous evidence indicates high prevalence of metabolic disorders in aging people [13, 32]. Gender remains a highly controversial factor associated with metabolic syndrome due to unmatched socio-demographic characteristics involved in different studies. The high sex ratio (W/M) in our study population could justify the male sex appearing in this study as an important protective factor against metabolic syndrome [OR, $0.22(0.1-0.45) ; \mathrm{p}<0.001]$. On the other hand, female sex had been reported as predicting factor of metabolic syndrome in many studies in Africa [23, 34].

Family history of metabolic and coronary heart disease was an independent predictor of metabolic syndrome in this study [OR, 2.24 (1.28-3.92); p, 0.004]. This finding is substantiate with a previous report [29]. The place of residence, ethnic group and smoking were not independent predictors of metabolic syndrome as reported by many authors [29, 35]. Adherence by $90 \%$ of the participants in this study to the nutritional education program as part of their follow-up at $\mathrm{BRH}$ would explain this result. However, strong association of alcohol consumption with metabolic syndrome in this study [OR, 4 (1.54-10.94); $\mathrm{p}, 0.004$ ] is consistent with the literature $[32,34]$.

Another important finding in this study was that, the nutritional supplement was negatively associated with metabolic syndrome [OR, 3.5 (1.75-7); $\mathrm{p},<0.001]$. Nutritional supplements (classified as probiotics and prebiotics) are modulators of the intestinal microbiota and, involved in lipids, carbohydrates and proteins metabolism [36].

This study was confronted with several limitations. Firstly, some ethnic groups of participants had insufficient number of patients required for statistical analysis and we considered the Bamileke ethnic group on the one hand, and all other ethnic groups on the other hand. Moreover, the predominance of women in this study would influence the association between the metabolic syndrome and gender. Secondly, the prescription of antiretroviral drugs in fixed-dose combinations did not allow the confirmation of the independent effect of a specific class of ARVs. In addition, a previous history of antiretroviral treatment may not be complete in many patients who were referred from other hospitals. Therefore the effects of antiretroviral drugs on metabolic syndrome may have been underestimated in our study. Thirdly, insufficient information on the probiotic and prebiotic values of the foods used by patients in the formulation of nutritional supplements, as well as the plants used to prepare the decoctions consumed by our 
patients limited the interpretation of the results. Fourthly, the internationally standardized questionnaires for assessing physical activity do not objectively define moderate and vigorous effort; therefore, the farm work that was one of the activities of almost all participants in this study, and that we considered vigorous physical effort may have been overestimated.

\section{Conclusion}

In conclusion, we were able to confirm the high prevalence rate of metabolic syndrome among HIV-infected patients at Bafoussam Regional Hospital in Cameroon. In this study, we found that Both HIV related factors and traditional factors are associated with metabolic syndrome. This work particularly highlights the association of the nutritional supplements and the traditional medicines with metabolic syndrome which appears as a pathological situation of multifactorial etiology and we recommend its systematic monitoring among all PLWHA.

\section{Contributions of the Authors}

J-RK, JPD, JMD and CWM participated in the design of study. JMD, CWM and AND collected the data. JMD, STL and EZM contributed to data analysis, interpretation and manuscript design. All authors contributed to the review and approved the final version.

\section{Conflicts of Interest}

All the authors do not have any possible conflicts of interest.

\section{Acknowledgements}

We acknowledge the Director and the staff of the HIV care centre and the laboratory unit of the BRH for their cooperation especially Dr Ngechop Joel, Dr Kemta Fidele, Mr. Fotie Rigobert, Mr. Moungang Ignace, Mrs. Youmbi Anne, Mr. Fotso Guy. We also thank Dr Ndounda Steve, Mr. Kengne Emmanuel, Mrs Bongnsai Florence and Mr. Nimpa Jesco for their support. We can't end without thanking the academic staff of Faculty of Sciences of the University of Dschang for his orientation.

\section{References}

[1] Alberti KGMM, Eckel RH, Grundy SM, Zimmet PZ, Cleeman JI, et al. Harmonizing the metabolic syndrome: a joint interim statement of the International Diabetes Federation Task Force on Epidemiology and Prevention; National Heart, Lung, and Blood Institute; American Heart Association; World Heart Federation; International Atherosclerosis Society; and International Association for the Study of Obesity. Circulation. 2009; 120: 1640-1645.

[2] Chambers JC, Eda S, Bassett P, Karim Y, Thompson SG, et al.
C-reactive protein, insulin resistance, central obesity, and coronary heart disease risk in Indian Asians from the United Kingdom compared with European whites. Circulation. 2001; 104: $145-150$.

[3] Fezeu L, Balkau B, Kengne A-P, Sobngwi E, Mbanya JC. Metabolic syndrome in a sub-Saharan African setting: central obesity may be the key determinant. Atherosclerosis. 2007; 193: 70-76.

[4] Grunfeld C, Pang M, Shimizu L, Shigenaga JK, Jensen P, et al. Resting energy expenditure, caloric intake, and short-term weight change in human immunodeficiency virus infection and the acquired immunodeficiency syndrome. Am J Clin Nutr. 1992; 55: 455-460.

[5] Shor-Posner G, Basit A, Lu Y, Cabrejos C, Chang J, et al. Hypocholesterolemia is associated with immune dysfunction in early human immunodeficiency virus-1 infection. Am J Med. 1993; 94: 515-519.

[6] Vujkovic-Cvijin I, Dunham RM, Iwai S, Maher MC, Albright $\mathrm{RG}$, et al. Dysbiosis of the gut microbiota is associated with HIV disease progression and tryptophan catabolism. Sci Transl Med. 2013; 5: 193 ra91.

[7] Mutlu EA, Keshavarzian A, Losurdo J, Swanson G, Siewe B, et al. A compositional look at the human gastrointestinal microbiome and immune activation parameters in HIV infected subjects. PLoS Pathog. 2014; 10 (2): e1003829.

[8] Irlam JH, Visser MME, Rollins NN, Siegfried N. (2010). Micronutrient supplementation in children and adults with HIV infection. Base de données des revues systématiques Cochrane; 12: CD003650

[9] Garcia OP. Micronutrients, immunology and inflammation effect of vitamin A deficiency on the immune response in obesity. Proceedings of the Nutrition Society. 5th International Immunonutrition Workshop 2012; 71: 290-297.

[10] Hsue PY, Joan CL, Franklin A, Bolger AF, Martin JN, et al. Progression of atherosclerosis asassessed by carotid intima media thickness in patients with HIV infections. Circulation. 2004; 109: 1603-1608.

[11] Ngatchou W, Lemogoum D, Ndobo P, Yagnigni E, Tiogou E, et al. Increased burden and severity of metabolic syndrome and arterial stiffness in treatment-naïve HIV+ patients from Cameroon. Vasc Health Risk Manag. 2013; 9: 509-516.

[12] Sterne JAC, Hernan MA, Ledergerber B, Tilling K, Weber R, et al. Long-term effectiveness of potent antiretroviral therapy in preventing AIDS and death: a prospective cohort study. Lancet. 2005; 366 (9483): 378-84.

[13] Wu P, Hung C, Liu W, Hsieh C, Sun H, et al. Metabolic syndrome among HIV-infected Taiwanese patients in the era of highly active antiretroviral therapy: prevalence and associated factors. J Antimicrob Chemother. 2012; 67 (4): 1001-1009.

[14] Jerico C, Knobel H, Montero M, Ordonez-Llanos J, Guelar A, et al. Metabolic syndrome among HIV infected patients: prevalence, characteristics, and related factors. Diabetes Care. 2005; 28 (1): 132-137.

[15] Elgalib A, Aboud M, Dimian C, Duncan A, Wierzbicki AS, Peters BS. The assessment of metabolic syndrome in UK patients with HIV using two different definitions: CREATE 2 study. CMRO. 2011; 27 (1): 63-69. 
[16] Mbunkah HA, Mirikin HD, Kukwah AT, Nfor O, Nkuo-Akenji T. Prevalence of metabolic syndrome in human immunodeficiency virus-infected patients from the South-West region of Cameroun, using the adult treatement panel III criteria. Diabetol Metab Syndr. 2014; 6 (1): 92

[17] Lepori M, Broccard FA, Schaller DM, Greub G. Acidose lactique chez les patients infectés par le VIH. Forum Médical Suisse. 2001; 38: 946-949.

[18] Morisky DE, Ang A, Krousel-Wood M, Ward HJ. Predictive Validity of a Medication Adherence Measure in an Outpatient Setting. JCH. 2008; 10 (5): 348-354.

[19] Craig CL, Marshall AL, Sjostrom M, Bauman AE, Booth ML, et al. International Physical Activity Questionnaire: 12-country reliability and validity. Med Sci Sports Exerc. 2003; 35: 1381-1395.

[20] Haskell WL, Lee I-M, Pate RR, Powell KE, Blair SN, et al. Physical activity and public health: updated recommendation for adults from the American College of sports medicine and the American Heart Association. Med Sci Sports Exerc. 2007; 39: $1423-1434$.

[21] World Health Organization. Measuring obesity: classification and description of anthropometric data. Copenhagen: WHO 1989 (Nutr UD, EUR/ICP/NUT 125).

[22] National Cholesterol Education Program (NCEP) Expert Panel on Detection, Evaluation, and Treatment of High Blood Cholesterol in Adults (Adult Treatment Panel III). (2002). Third Report of the National Cholesterol Education Program (NCEP) Expert Panel on Detection, Evaluation, and Treatment of High Blood Cholesterol in Adults (Adult Treatment Panel III) final report. Circulation; 106: 3143-3421.

[23] Dimodi HT, Etame LS, Nguimkeng BS, Mbappe FE, Ndoe NE, et al. Prevalence of metabolic syndrome in HIV-Infected Cameroonian patients. World J AIDS. 2014; 4: 85-92.

[24] Mapoure YN, Nkongni IN, Luma HN, Ngahane BHN, Barla E, et al. Incidence des accidents vasculaires cérébraux chez les patients VIH positifs sous traitement antirétroviral au long court. Pan Afr Med J. 2016; 24: 45.8013.

[25] Mbanya D, Sama M, Tchounwou P. Current Status of HIV/AIDS in Cameroon: How Effective are Control Strategies? Int. J. Environ. Res. Public Health. 2008, 5 (5): 378-383.

[26] Garcia-Calleja JM, Mvondo JL, Abbenyi SS, Zekeng L, Loius
JP, et al. Profil de l'épidémie VIH/SIDA au Cameroun. Bull. Liais. Doc. OCEAC. 1992; 99: 31-33.

[27] Ntusi NAB \& Ntsekhe M. Human immunodeficiency virus-associated heart failure in sub-Saharan Africa: evolution in the epidemiology, pathophysiology, and clinical manifestations in the antiretroviral era. ESC Heart Failure. 2016; 3: 158-167.

[28] Enyegue DM, Ngondi JL, Fomekong GI, Agbor G, Oben JE. Prediction and prevalence of metabolic syndrome in overweight and obese subject in cameroon. Int $\mathrm{J}$ Biomed Pharmaceut Sci. 2008; 2 (2): 117-121.

[29] Ntentie FR, Ngondi JL, Azantsa KBG, Santy EV, Dimodi HT, et al. Urbanization and metabolic syndrome in Cameroon: alertness on less urbanised areas. Endocrinol Metab Syndr. 2014; 3: 137

[30] Thienemann F, Sliwa K, Rockstroh JK. HIV and the heart: the impact of antiretroviral therapy: a global perspective. Euro Heart J. 2013; 34 (46): 3538-3546.

[31] Bernal E, Masia M, Padilla S, Gutierrez F. High-density lipoprotein cholesterol in HIV-infected patients: evidence for an association with HIV-1 viral load, antiretroviral therapy status, and regimen composition. AIDS Patient Care STDs. 2008; 22 (7): 569-575.

[32] Alencastro PR, Fuchs SC, Wolff FH, Ikeda ML, Brandao ABM, et al. Independent Predictors of Metabolic Syndrome in HIV-Infected Patients. AIDS Patient Care STDs. 2011; 24 (11). 627-634.

[33] Boulougoura A \& Sereti I. HIV infection and immune activation: the role of co-infections. Curr Opin HIV AIDS. 2016; 11 (2): 191-200.

[34] Alassani A, Dovonou CA, Sossou E, Attinsounon CA, Gninkoun J, et al. Prévalence, facteurs associés et prédisposant au syndrome métabolique chez les personnes vivants avec le VIH sous traitement antirétroviral à Porto-Novo en 2014. Pan Afr Med J. 2015; 22 (1): 296.7923

[35] Mandob DE, Fomekong GID, Ngondi JL. Prevalence of metabolic syndrome among Bamileke ethnic women Yaounde, Cameroon. Int J Pharm Bio Sci. 2013; 4 (4): (B) 255-262.

[36] Kovatcheva-Datchary $\mathrm{P} \&$ A Arora T. Nutrition, the gut microbiome and the metabolic Syndrome. Best Pract Research Clin Gastroenterol. 2013; 27: 59-72. 